\author{
Professor Adrian MICU \\ E-mail: adrian.micu@ugal.ro \\ Professor Alexandru CAPATINA \\ E-mail: alexandru.capatana@ugal.ro; \\ Department of Business Administration \\ Dunarea de Jos University of Galati, Romania \\ Associate Professor Angela-Eliza MICU \\ E-mail: angelaelizamicu@yahoo.com \\ Department of Business Administration \\ Ovidius University of Constanta, Romania \\ Marius GERU \\ E-mail: marius.geru@thecon.ro \\ Department of Marketing \\ Transilvania University of Brasov, Romania \\ Professor Kamer Ainur AIVAZ, \\ Department of Economics \\ Ovidius University of Constanta, Romania \\ Associate Professor Mihaela Carmen MUNTEAN \\ E-mail: Mihaela.muntean@ugal.ro \\ Department of Economics \\ Dunarea de Jos University of Galati, Romania
}

\title{
A NEW CHALLENGE IN DIGITAL ECONOMY: NEUROMARKETING APPLIED TO SOCIAL MEDIA
}

Abstract. Being able to test disruptive business models is today's gamechanger in the expected business environment. Moreover, today's digital economy demands insightful, actionable data from consumers into the increasingly accountable managerial hands of marketers in order to speed up the decision-making process. Social media is the de facto indicator in measuring consumer engagement and public understanding of products and brands in the expanding digital economy. Even so, up to this point, it is defined as an industry challenge or social enigma how social media content grows viral and what are the factors to consider when crafting the next giant digital brands. This article aims at conducting a systematic literature review (SLR) on how neuromarketing can act as a precursor of social media communication for gaining leverage in a more competitive and noisier environment. The SLR methodology provides instruments to analyze the emotional and physiological states of users, assessing quantitative studies on the data collected.

Keywords: Neuromarketing, social media, digital transformation, digital economy.

JEL Classification: M31, D87 
Adrian Micu, Alexandru Capatina, Angela-Eliza Micu, Marius Geru, Kamer Ainur Aivaz, Mihaela-Carmen Muntean

\section{Introduction}

Neuromarketing is an emerging field of study that can tackle this challenge and can help researchers better understand how to communicate in social networks beyond screens and complicated computed code. The goal of this paper is to identify actual neuroscience behavioural data intended to be correlated with the cognitive processes of social media users. Based on this understanding, marketing managers can automate complex decision-making functions or validate social media content before publishing.

There is few amount neuromarketing of research that investigates its real impact on social media campaigns. This study aims at bringing body of knowledge one step further on the pathway towards bridging the gap in consumer behaviour analysis and neuromarketing techniques. Neuromarketing's capability to understand consumer emotions plays an essential role in the acceptability of the social network user. Furthermore, content on social media can gain more awareness using neuroscience ability to fine-tune marketing messaging.

The outcome of this research is represented by a collection of managerial recommendations on social media platforms relying on serendipitous information and quality content in the emerging digital economy. The selection of relevant eligible literature on neuromarketing applied to social media was performed with a systematic, evidence-informed literature review. Following the guidelines suggested by Tranfield et al. (2003), the researchers excluded articles which do not disclose sufficient details of the application of neuroscience methods in social media in order to implement a quality assessment (Kraus et al., 2018).

The remainder of this article is as it follows: after a careful consideration of relevant body of knowledge focused on neuromarketing, social media and digital economy, we performed a systematic literature review on these topics and subsequently in-depth analyses reflecting neuroscience research methods applied to social media and digital commerce that provide relevant theoretical and practical implications.

\section{Theoretical Background on Social media impact in digital commerce}

Consumers perceive the use of social media and digital commerce solutions as tools enabling convenience, efficiency in product research, more prosperous and more participatory information, a more comprehensive range of products and prices (Bayo-Moriones and Lera-Lopez, 2007). Online social networks tend to increase these benefits because consumers can communicate proactively. For example, through online social networks, people can search the opinions of other online shoppers about specific products. In this way, consumers value the judgments of colleagues more than their preferences, which indicates an external persuasive power, and the latest trends in marketing are based on these emotions concerning user interactions in decision making. 
The ease of interaction and the network of friends or relatives on social networking websites brings audiences and brands closer with a high level of trustworthiness and naturalness (Schouten et al., 2020). This was done previously only by actors and pop singers, and today on Instagram or Facebook, everyone is two clicks away from an influencer. Marketers are building campaigns in such a way that users have to like or share a specific piece of content in order to gain benefits. Of course, these campaigns can lead to undesired outcomes and can affect brand image. It is essential to balance the benefit with the targeted audience and have a transparent framework for the rewards offered.

The social presence of online brand community, community members, and the interaction between both create social cues and allow users to build relationships. The fully mediated relationship of all three social presence dimensions is also in line with results from Lu et al. (2016), who studied the effect of all three dimensions on trust in online sellers and subsequently on purchase intentions. Social cues perceived by the online brand community are primarily attributed to the technological environment. These cues thus create transparency and lower uncertainty, leading to an increased level of trust. Voorveld (2019) confirms that influencer marketing business model is a good strategy for targeting generation $\mathrm{Z}$, marketers and big brands are paying as much as a monthly budget of digital advertising on a 10-minute video of a product review. Influencers have the means to communicate and add value to specific features of a product that can bring the brand closer to consumers (Schouten et al., 2020). The most important benefit is that this communication channel comes with the creation of the content out of the box, companies are not required the employment of agencies to develop the advertising. Influencers are now included in digital communication strategies in order to strengthen brand loyalty and new products awareness. Launching new products with the help of influences is the hot new trend in obtaining an excellent initial review of the product.

Usage of social media platforms has enabled people to have a common voice against government and brands, improving the standard of living across cultures (Moreno et al., 2016). Generation $\mathrm{Z}$ may begin to associate themselves to more prosperous people, which can point to perceptions of submission and depression according to social comparison theory (Festinger, 1954). Time spent on social media can also replace face-to-face communication and produce depression due to the absence of social support (Cohen and Wills, 1985), which may increase the social media-depression connection. Social media can also be used to communicate images of adolescents involved in illegal acts such as underage drinking, fighting, stealing, graffiti painting and risky driving, and can give an exaggerated impression of how common such behaviour is. If the people involved in a crime on social media are perceived as role models, their role may be copied, which is according to social learning principles (Bandura, 1971).

Wang et al. (2020) suggest that social media is dominated by weak ties, and individuals with low trust propensity may not trust other online users easily so 
Adrian Micu, Alexandru Capatina, Angela-Eliza Micu, Marius Geru, Kamer Ainur Aivaz, Mihaela-Carmen Muntean

they are cautious about online knowledge sharing. With the increasing adoption trend of social media use, social commerce is gaining popularity, enabling collaborative approaches in online commerce activities that are possible by the effective use of knowledge sharing activities in co-creation processes (Bugshan and Attar, 2020).

\section{Theoretical Background on Neuromarketing}

One of the most critical aspects of marketing is knowing what customers want, what they react to, what attracts them, and, most importantly, what they need. Marketing research has traditionally meant customer interviews, focus groups and surveys, among other declarative techniques that offer an insight into the customer's preferences through behaviour demonstrated or verbalized.

These traditional research techniques have been deemed unreliable because of the inability or unwillingness of participants to offer accurate information about their emotions and preferences when presented with an advertisement, resulting in the majority of the 400 billion dollars invested each year in advertising campaigns to be lost. (Morin, 2011) This research problem is being gradually resolved through the integration of neuroscientific study. The problems that arise with cognitive or conscious participation are resolved once marketing researchers turn to study the physiological responses that are not biased or as influenced or unreliable as conscious feedback from participants.

The neuroscientific approach of marketing aims to study the cerebral mechanism in order to understand better aspects of human behaviour such as decision-making, preference, attention and the effects of certain intense emotions caused by advertisements (Levallois et al., 2019). Using the knowledge gathered by using neuromarketing techniques leads to more profitable marketing campaigns that put businesses on the path of success. Although there are many tools used in neuroscience the most used and successful techniques in neuromarketing are the following.

\section{Electroencephalogram (EEG)}

One of the main methods to record brain neural activity is the electroencephalogram (EEG). Being portable and relatively economical, the EEG is used to register the brain's electrical activity through sensors placed noninvasively on the scalp. The registered data is then analysed and interpreted in a set of dimensions: engagement, attention, memorization and other emotional reactions. Moreover, the EEG is comfortable for the user in order to capture natural behaviour and, thus, reliable results. These results are used to predict the user's decision-making incidence with an accuracy higher than $87 \%$ and distinguish between the "Like" and "Dislike" preferences of the user with over $63 \%$ accuracy. (Golnar-Nik et al., 2019)

Functional magnetic resonance imaging (fMRI)

Another promising tool in the study of neuromarketing is the Functional Magnetic Resonance of fMRI. The fMRI measures brain activity through changes 
in the user's blood flow in particular regions of the brain with high precision. Through this technique, researchers can find the areas of the user's brain that receive and use the most amount of oxygen when shown different specific stimuli (Ruanguttamanun, 2014). Even though this neuromarketing technique provides a three-dimensional map of the brain which can distinguish each cortical structure with its activity, it lacks high temporal resolution. Moreover, this practice is expensive and intrusive (the user must lie still for long periods in order to record the variation of the blood oxygen levels in the brain). Compared to the comfortable headgear of the EEG, the fMRI may present less accurate data relevant to marketing decision making.

Eye tracking

Another frequently employed technique is Eye Tracking (ET). Through this technique, researchers register and analyze eye movement using infrared light that identifies the position of the pupil. While the user is subject to several stimuli, the eye tracker recognizes gaze patterns that suggest attention and interest. This technique is used in neuromarketing to measure user's engagement with advertisements in order to deduce factors that transform visitors into customers. With the increase of advertisement saturation, it has become harder to attract the eye of the customer and to stir their curiosity. The eye-tracking technique is one of the most efficient tools in neuromarketing, provided it is used with reliable participants.

\section{Facial coding}

In addition to the activity of the brain, important information can be found by studying the voluntary or involuntary movements of the face mussels. Even though they are most often subtle, the movements of the face muscles convey a tremendous amount of information about the user's preferences and emotions when faced with stimuli. Facial coding (FC) is one of the techniques used in neuromarketing to register and analyze the micromovements of the face. Unlike the electromyogram (EMG), which is an intrusive and expensive method of studying facial reaction through the use of sensors that register the electrical response produced by muscles, FC is an inexpensive and portable technology that only requires a camera. The micro expressions of the participants are registered by the camera to be later analyzed and attributed to specific emotional and cognitive states. Facial coding is regarded as one of the most effective methods of analyzing and measuring certain emotions, such as distress, being used for studying pain levels and distinguishing between physical and psychological distress in infants. (Kohut and Riddell, 2009) Not being an intrusive method, facial coding does not restrict the user's movement and, therefore, does not influence the facial response, providing natural, unaltered results. Nevertheless, FC loses precision by not measuring the electrical response of the muscles and only relying on the camera. As any neuroscientific method, facial coding relies on the quality of technology, participant willingness and capability to cooperate, data processing, and many other internal and external factors. 
Adrian Micu, Alexandru Capatina, Angela-Eliza Micu, Marius Geru, Kamer Ainur Aivaz, Mihaela-Carmen Muntean

Magnetoencephalography (MEG)

Besides electrical activity, researchers can also study the magnetic activity in the brain in order to gather data. Magnetoencephalography (MEG) is the technique through which the magnetic activity of the user's brain is registered while being exposed to specific stimuli through a helmet with a number of 100 to 300 sensors. This helmet detects fluctuation in magnetic fields that are influenced by the electrical activity of the brain. (Morin, 2011) MEG is effective in offering a high temporal resolution that enables researchers to detect subtle changes in brain activity (Morin, 2011), correlating them with the stimuli the user is presented with. Comparatively, MEG is a more expensive method of registering the brain's psychological activity of the CNS than the more popular EEG, thus being seldomly employed. Moreover, the technique in question is not portable. This method requires experiments to be carried out in a laboratory setting, which may interfere with the validity of the results.

\section{Galvanic Skin Response (GSR)}

Other than brain activity, eye movement, and movement of the face muscles, the participant's skin is also a source of information. One of the effects of intense emotions, such as excitement or fear, on the human body, is perspiration. When the participant is faced with a stimulus that generates powerful emotions, the endocrine glands activate, increasing the skin's electrical conductivity. The Galvanic Skin Response (GSR) aims to register the changes in skin perspiration and is used in neuromarketing to determine what kind of marketing stimuli are psychologically exciting (Ohme et al., 2011). This method did not gain serious attention in marketing research, only five articles were identified using this technique in social media consumer's behaviour.

Electrocardiogram (ECG)

Another physiological response to intense emotional and cognitive states is the increase in heart rate as the participant is exposed to exciting stimuli their pulse increases in order to provide adequate blood flow and oxygenation to the brain. The Electrocardiogram (ECG) registers fluctuation in heart rate through sensors placed on the skin and is often used alongside the GSR because of their ability to analyses in real-time the emotional state of the user. Moreover, it is an inexpensive and not very intrusive method of study with which most participants feel comfortable, making ECG an efficient and reliable technique of gathering data frequently used in neuromarketing study.

\section{Methodology}

The systematic literature review is frequently utilized in marketing and management academic literature in order to assess the current state of research regarding specific topics. Neuromarketing and social commerce are two emerging areas that need the attention of a study using SLR methodology. The selection of steps concerning this methodology requires a good understanding of the topics, and it helps in the gathering of a vast set of publications and management of immense 
amounts of content. The analysis step by step process refers to the performance of a critical and careful examination of the publications to identify patterns and recurring themes. This review includes 131 papers covering the usage of neuroscience methodology in the analysis of various social media networks and digital commerce platforms. The study was conducted to monitor the advances in consumer behavior, specifically concerning the intention to buy products online using neuromarketing techniques. The SLR method enables a decent degree of objectivity, as well as procedural and analytical replicability using the following steps:

- Definition research questions;

- Search and selection of academic journals;

- Critical assessment research topics;

- Data analysis and concretization.

Alongside the emergence of the internet and social media, a new era of business and marketing has begun. On these fertile new grounds of human interaction, digital marketing has thrived and become a very competitive field. Social media is the battleground of advertisers who fight for the fleeting attention and interest of users. Even though advertisers are enjoying the tremendous potential of online marketing, they have to face the overwhelming competition and to overcome the effects of advertisement saturation on potential customers. By using neuromarketing techniques to understand their target audience, advertisers have a greater chance of catching the eye of customers. Based on these assumptions, the following research questions are formulated: commerce?

Q1: Can neuromarketing be used as a tool to optimize social media

Q2: What are the main areas of research related to neuromarketing and what methods are used in social media and digital commerce?

Q3: Which areas need to be improved in line with the usage of neuromarketing analysis in social media and digital commerce?

Q4: Which types of content can be improved using neuromarketing: ex. images, text, video, design of pages?

For this research, several searches were performed (listed in Table 1) in order to identify all articles related to neuroscience, social media and digital commerce in marketing journals. Using the search function on the platforms: google scholar, science direct and research gate were identified 1385 academic articles related to these topics. Using the references and bibliography section of these articles, the list was extended with another 897 relevant items. All 2282 articles included in the research contained at least one of the targeted key phrases in the abstract or content. For specific keywords, several variations were added for the search function in order to increase the number of results (ex. Eye tracking, includes the variations eye-tracking, eye tracker and eye-tracker) - Table 1. 
Adrian Micu, Alexandru Capatina, Angela-Eliza Micu, Marius Geru, Kamer Ainur Aivaz, Mihaela-Carmen Muntean

Table 1. Keywords used in the research

\begin{tabular}{|l|l|l|l|l|}
\hline \multicolumn{1}{|c|}{$\begin{array}{c}\text { Neuromarketing } \\
\text { keywords }\end{array}$} & \multicolumn{1}{|c|}{$\begin{array}{c}\text { Social } \\
\text { keywords }\end{array}$} & \multicolumn{1}{|c|}{$\begin{array}{c}\text { Digital } \\
\text { content }\end{array}$} & ecommerce & $\begin{array}{c}\text { Specific } \\
\text { social } \\
\text { platform }\end{array}$ \\
\hline EEG & social media & website & $\begin{array}{l}\text { digital } \\
\text { commerce }\end{array}$ & Facebook \\
\hline fMRI & social network & web design & ecommerce & Instagram \\
\hline Eye-tracker & Social posts & $\begin{array}{l}\text { web } \\
\text { development }\end{array}$ & e-commerce & Youtube \\
\hline Neuroimaging & viral content & blog & online shopping & TikTok \\
\hline Facial coding & viral video & internet & online store & Reddit \\
\hline $\begin{array}{l}\text { Positron-emission } \\
\text { tomography }\end{array}$ & viral post & online & $\begin{array}{l}\text { digital } \\
\text { commerce }\end{array}$ & Twitter \\
\hline $\begin{array}{l}\text { MEG, GSR, ECG, } \\
\text { PET }\end{array}$ & $\begin{array}{l}\text { social } \\
\text { commerce }\end{array}$ & digital content & buy online & Pinterest \\
\hline Electrocardiogram & online reviews & digital images & click to buy & Snapchat \\
\hline $\begin{array}{l}\text { Functional Magnetic } \\
\text { Resonance }\end{array}$ & user posts & video & add to cart & Tumblr \\
\hline $\begin{array}{l}\text { Magnetoencephalogr } \\
\text { aphy }\end{array}$ & Hashtag & web 2.0 & product page & LinkedIn \\
\hline $\begin{array}{l}\text { Galvanic skin } \\
\text { response (GSR) }\end{array}$ & Share button & Blog post & checkout & Quora \\
\hline $\begin{array}{l}\text { Steady State } \\
\text { Topography (SST) }\end{array}$ & User Story & vlogging & $\begin{array}{l}\text { Online } \\
\text { commerce }\end{array}$ & Meetup \\
\hline
\end{tabular}

Source: Authors

For this research we have used the methodological process of conducting framework synthesis using the nVivo software. It can be stated that NVivo is suitable for framework synthesis and works well for working on qualitative data. The query tools within NVivo can facilitate sensitivity analysis in order to check the impact of specific keywords using the automatic labelling feature. The software can also be used to enhance and illustrate the relations of specific topics and manage an extensive quantity of academic content. One of the features that nVivo offers is the clustering of the papers based on word similarity and the ability to 
A New Challenge in Digital Economy: Neuromarketing Applied to Social Media

compare coding references between articles. Visualizing elements coded by color helps to understand the relation of topics better (Figure 1).

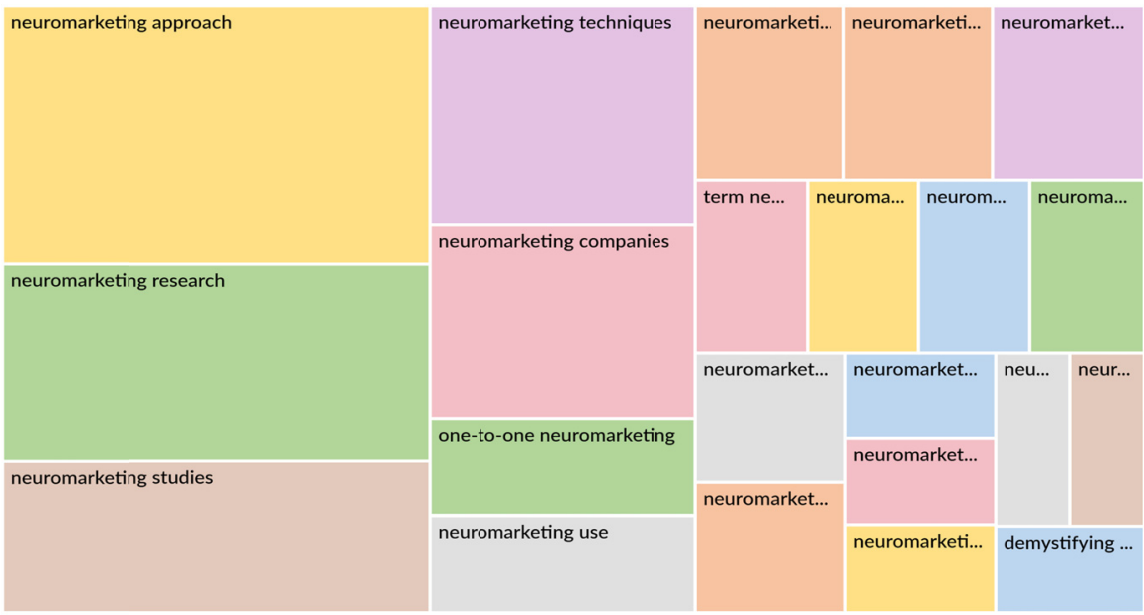

Figure 1. Document coding on the topic of neuromarketing Source: nVivo software output

\section{Findings}

One of the major findings of this research was that the academic articles were spanned on a broad number of journals. None of the 84 journals identified was dedicated to neuromarketing, and the only special issue on neuromarketing was in "Der markt", Volume 49 (International Journal of Marketing) in 2010. Considering this topic was not very popular at that time, only eight articles were published, more than half being in German language. A targeted search on content related to neuromarketing research on social media reveals the findings reported in Table 2.

Table2. Occurrences of journals with neuromarketing research on social media content

\begin{tabular}{|l|c|}
\hline Journal name & Occurrences \\
\hline Journal of Retailing and Consumer Services & 5 \\
\hline Journal of Business Research & 4 \\
\hline Physiology \& Behavior & 4 \\
\hline European Journal of Marketing & 3 \\
\hline Applied Soft Computing & 2 \\
\hline Australasian Marketing Journal (AMJ) & 2 \\
\hline Cognitive Prosthetics & 2 \\
\hline
\end{tabular}


Adrian Micu, Alexandru Capatina, Angela-Eliza Micu, Marius Geru, Kamer Ainur Aivaz, Mihaela-Carmen Muntean

\begin{tabular}{|l|c|}
\hline \hline Journal name & Occurrences \\
\hline Congreso Internacional de Innovación y Tendencias en Ingenieria & 2 \\
\hline Cyberpsychology, Behavior, and Social Networking & 2 \\
\hline
\end{tabular}

Source: Authors

Contrary to the general interest in the last two years, neuromarketing research gained more interest. Comparing the occurrence from academic articles with the google trends score that aggregates the monthly volume of searches in an indicator on a scale from 0 to 100 we can see that the academic research is on an ascending trend (Figure 2).

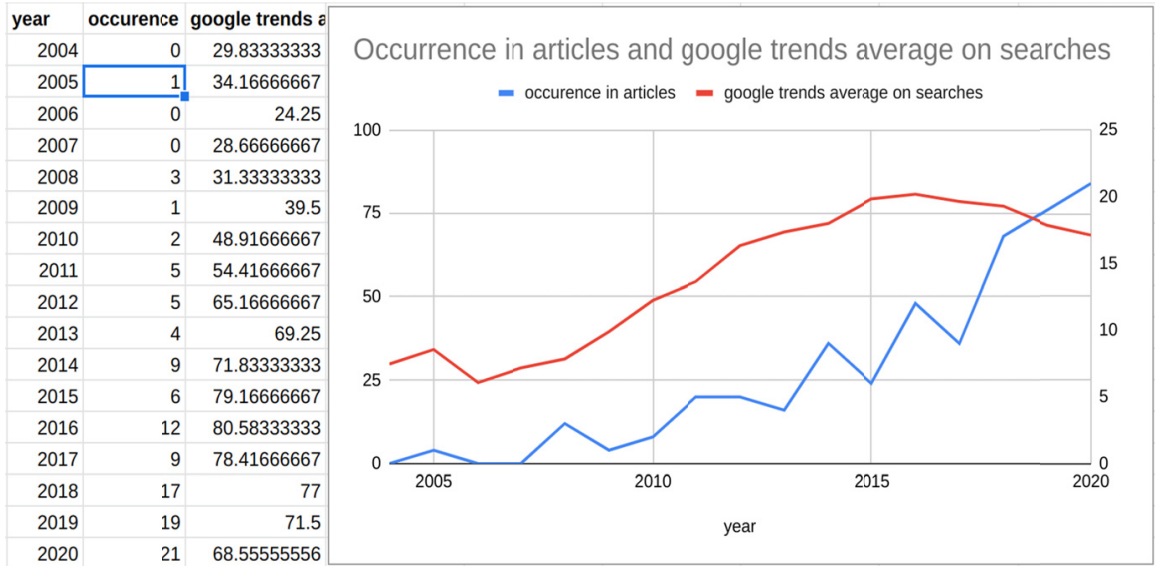

Figure 2. Articles in comparison to google trends yearly average Source: Google Trends

The gap in interest can be explained by the fact that neuromarketing is a sensitive subject, and when it gains media attention, a general audience starts looking for the information online. Another factor is that Google search engine is not widely adopted in China and other Asian countries, out of the ten articles published in China, only two of them are published before 2018 .

By far the most interested in the application of neurosciences in social media and digital commerce is in North America and the European countries (Figure 3). The increased competition in fast-moving consumer goods drives the motivation for using more advanced methods and technologies in understanding consumer behavior. 
A New Challenge in Digital Economy: Neuromarketing Applied to Social Media

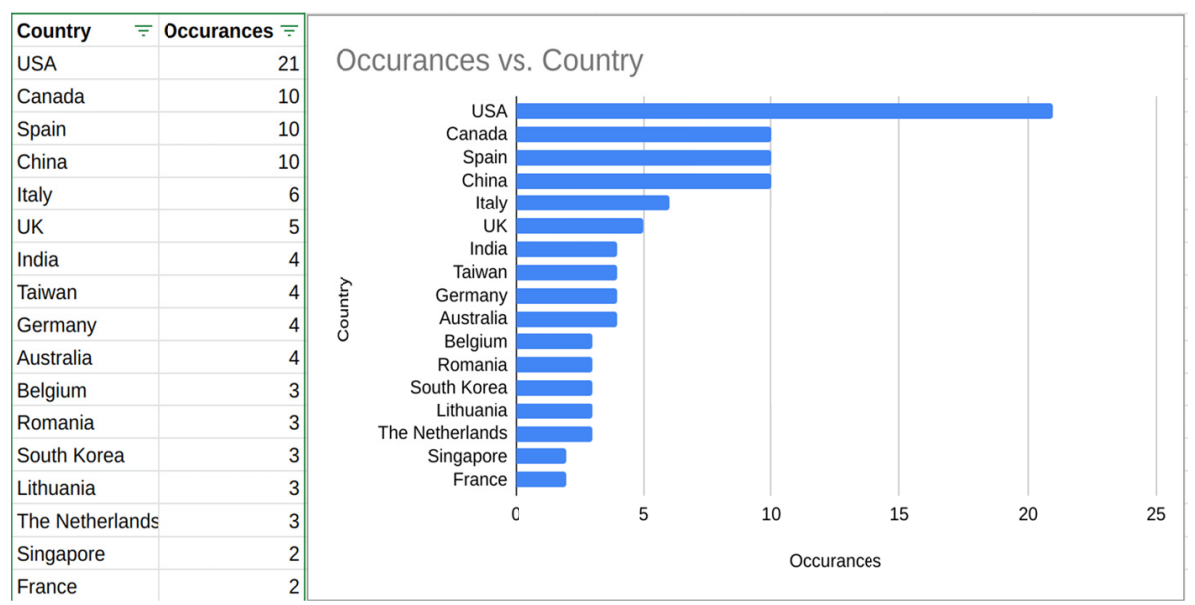

Figure 3. Publications by country

Source: spreadsheet and python analysis

Electroencephalogram and Functional magnetic resonance imaging are the two most used neuromarketing techniques in analyzing social media e-commerce content, as shown in table ZZ. An impressive output from the keywords research is that most of the content analysis is on digital videos, YouTube having 21 occurrences in nine articles in the research. With a similar number of articles but with 22 occurrences is the most popular social network Facebook followed by Instagram (7 results in two articles) - Table 3. Online videos are of particular importance within the digital marketing mix of start-ups. Videos have a high media richness that allows an enhanced communication of several personalized and emotional aspects of marketing messages. This allows practical applications of online video content for external traffic generation as well as conversion rate optimization at relevant touchpoints of a customer journey or right at the point of sale. Taking this into account, we can answer to fourth research question, considering videos one of the most used pieces of content that can be optimized with neuromarketing. More important is that digital video content can be used both on social media websites and e-commerce platforms as well.

Table 3. Occurrences by methods and content and other keywords

\begin{tabular}{|l|c|c|c|}
\hline Keywords & Occurrences & No. of Articles & Match in title \\
\hline online & 1589 & 119 & 11 \\
\hline social & 2425 & 104 & 11 \\
\hline neuromarketing & 1285 & 83 & 22 \\
\hline EEG & 1899 & 75 & 17 \\
\hline fMRI & 824 & 73 & 6 \\
\hline
\end{tabular}


Adrian Micu, Alexandru Capatina, Angela-Eliza Micu, Marius Geru, Kamer Ainur Aivaz, Mihaela-Carmen Muntean

\begin{tabular}{|l|c|c|c|}
\hline Keywords & Occurrences & No. of Articles & Match in title \\
\hline website & 822 & 68 & 3 \\
\hline video & 665 & 66 & 1 \\
\hline neuroimaging & 273 & 58 & 1 \\
\hline social media & 327 & 48 & 2 \\
\hline internet & 158 & 44 & 0 \\
\hline social network & 178 & 39 & 0 \\
\hline e-commerce & 458 & 38 & 9 \\
\hline online shopping & 181 & 33 & 1 \\
\hline eye tracking & 122 & 33 & 1 \\
\hline
\end{tabular}

Source: jupyter lab python

The next noticeable neuromarketing type of analysis as a result of the research is eye-tracking with 122 occurrences in 33 articles. Eye-tracking is a valuable method for studying consumer behavior on e-commerce websites. This analytical method usually includes the study of the visual focus characteristics of specific calls to action elements and design patterns.

The directions of neuromarketing and sensory marketing have emerged to learn better how customers' attention, emotions, choices, memories, preferences and consumption are influenced by sensory and unconscious methods, to appeal to them more efficiently. The intention of building and improving an online customer's experience is now possible with considerable investigation insight on the effectiveness of subtle sensory tactics and through the use of neuroscientific measurement techniques. Commencing from the first research question, we can say that there is increasing interest regarding the implications of these complex tactics and subconscious analysis tools for the long-term wellbeing of clients on social networks who might not be completely aware of their cognitive processes.

Online customers are exposed to thousands of products and digital marketing communications, on the web and more specifically on social media platforms in a typical day. The abundance of information and options makes consumption choice processes more complex. Furthermore, the marketplace is characterized by high levels of "brand parity," where many products provide similar (if not the same) functional benefits (Muncy, 1996). Customers no longer purchase products solely for their functional and monetary value, but also base their decisions on their experiential aspects, as promised by brands (Schmitt, 1999). In an attempt to avoid brand parity, firms try to establish a favorable and different total customer experience by integrating the affective, symbolic, experiential, sensory, and functional attributes of their products (Haeckel et al., 2003). 
Acquiring such significant results of the minor act of impact on product evaluations and interpersonal compliance, marketers may quite favourably use them as tactics to persuade their consumers' perceptions on social media or to determine them to buy more online. However, such results require expensive equipment (Constantinescu et al., 2019) and usually, there is a need for a lengthy integration period. Solving this issue tackles research question number 3, there is no established framework and standards that allow marketers to replicate the results obtained by other researchers. There is a need for acquiring technical equipment and having lengthy research sessions in order to get applicable results. Usually, eCommerce and social media analytics tools use data previously collected in order to help marketers gain insightful knowledge about the audience that is visiting the website.

\section{Discussions and conclusions}

Social media has grown significantly in the last years, and accessing social network platforms like Twitter, Facebook, LinkedIn, Instagram and YouTube have become very convenient for users to use for entertainment or marketing campaigns. One in seven people on the planet has created a Facebook profile, and four out of five people have registered on at least one social network. In contrast with traditional marketing channels like TV, radio and print, social media, it has a low barrier to entry, and at least for now is considered the most powerful tool to engage with consumers. Knowing that companies are striving to obtain and engage clients that are willing to share their knowledge and ideas about products on social media.

The purposes of this study were to provide a comprehensive mapping of neuromarketing applications in social media research and to examine in this context the growing stream of research dedicated to digital marketing.

The findings reported in our study are consistent with optimization of the Acceptability and Awareness process in the customer-oriented 4A marketing framework, as described by Sheth and Sisodia (2012) and Kotler et al. (2016). Moreover, the results from our study are in line with the ideas shared by Constantinescu et al. (2019), who outline that neuromarketing research requires specific equipment and software as least intrusive as possible, but capable of capturing all nuances of consumer behaviour. A very challenging issue outlining that neuromarketing techniques decide which witnesses are allowed to speak and which actors should be silenced in social media (Brenninkmeijer et al., 2020) is discussed in our study on diverse psychological perspectives.

Managing the social media content correctly, the desired marketing message can reach thousands of friends or followers with one click of the mouse. On the other hand, one social media campaign can gain huge budgets rapidly, not reaching the desired objectives. Our findings are related with those reported by Mičík and Kunešová (2020), who highlight which factors influence the perceived attractiveness of the social media content, what in their point of view users of social networks liked and shared content and how to improve the social media pages so that they better serve their purpose. 
Adrian Micu, Alexandru Capatina, Angela-Eliza Micu, Marius Geru, Kamer Ainur Aivaz, Mihaela-Carmen Muntean

Neuroscience helped to illustrate that viral social media posts with high levels of user engagement are mostly owned by influencers that understand and use specific frameworks to target specific audiences. As shown by Sheldon and Bryant (2016), generation $\mathrm{Z}$ consider it is essential to edit or filter self-portrait photographs (selfies) to the point of highest appeal. This behavior might have negative psychological consequences creating different versions of the self-perceived image.

One of the most successful examples of how neuromarketing is used in social media is influencer marketing. Most of social media users are people of ages between 16 and 30, and among these, 68\% of them follow influencers (MañasViniegra, et al., 2020). The psychological effect is that if the brand associates their product with an online personality, the customers will both consciously and unconsciously identify that product with the influencer they follow and thus identify the product with the positive emotions they feel towards the influencer. This type of branding also helps humanize the brand, which is very important for consumer engagement. Using Electroencephalogram and Functional magnetic resonance imaging on social media content can help marketers gain valuable insights on how to optimize their content better. Considering the second research question, converting existing content into digital video content can be a good strategy considering most of the research in neuroscience is done explicitly on this topic.

For a brand to untap the full marketing potential of social media, it has to display a unique voice and personality through which it can communicate and connect to its consumers. Advertisers can produce intense emotions with which customers will associate the brand through humour, dramatic and emotional campaigns, addressing social, economic or environmental problems and taking part in charities. All these traits that a brand can employ in their online presence serve to create a sense of community between the company and its customers and ultimately determine consumers to identify with the brand itself.

In a time when there seem to be virtually endless sources to choose from in developing new business, the focus of marketing has shifted from the functionality of the product to how that product makes the consumer feel. Emotion being the more challenging to predict aspect of human behaviour, neuromarketing techniques have proven to be the helping tool for creating more successful marketing campaigns.

This research highlights neuroscience research methods applied to social media and digital commerce and managerial implications resulted. In the articles it was identified that Electroencephalogram and Functional magnetic resonance imaging are the most used neuromarketing methods usually applied in analysing social media and video content. Furthermore, that specific method like eye-tracking is especially used in research papers related to e-commerce. In the past few years, a gap emerged between the interest of the general audience and scientific community regarding neuromarketing. One of the main limitations of these articles is the lack of data and research on user privacy concerns and how further analysis frameworks should be developed. Further research is needed in order to understand how 
A New Challenge in Digital Economy: Neuromarketing Applied to Social Media

neuromarketing research can be reused and applied in different contexts once the knowledge is gained on a specific audience. Of course, this comes with privacy concerns that are the main factors driving interest for the public at large and should receive adequate consideration. First, a quantitative research is needed on how to better use the identified neuromarketing methods in social media and e-commerce. Second, a future study focused on Qualitative Comparative Analysis (QCA) method will facilitate to identify different configurations of causal recipes affecting the in-depth analysis of social media users' behaviour.

\section{ACKNOWLEDGEMENTS}

This research was conducted within the framework of the project FutureWeb, launched by Romanian Ministry of Research and Innovation, CCCDI - UEFISCDI, project number PN-III-P1-1.2-PCCDI-20170800/86PCCDI/2018, within PNCDI III.

\section{REFERENCES}

[1] Bandura, A. (1971), Vicarious and Self-reinforcement Processes. The nature of reinforcement, 228278;

[2] Bayo-Moriones, A. \& Lera-López, F. (2007), A Firm-level Analysis of

Determinants of ICT Adoption in Spain. Technovation, 27(6-7), 352-366;

[3] Brenninkmeijer, J., Schneider, T. \& Woolgar, S. (2020), Witness and Silence in Neuromarketing: Managing the Gap between Science and Its Application. Science, Technology, \& Human Values, 45(1), 62-86;

[4] Bugshan, H. \& Attar, R. W. (2020), Social Commerce Information Sharing and their Impact on Consumers. Technological Forecasting and Social Change, 153, 119875; [5] Cohen, S. \& Wills, T. A. (1985), Stress, Social Support, and the Buffering Hypothesis. Psychological Bulletin, 98(2), 310 ;

[6] Constantinescu, M., Orindaru, A., Pachitanu, A., Rosca, L., Caescu, S.-C. \& Orzan, M. C. (2019), Attitude Evaluation on Using the Neuromarketing Approach in Social Media: Matching Company's Purposes and Consumer's Benefits for Sustainable Business Growth. Sustainability, 11(24), 7094.

[7] Festinger, L. (1954), A Theory of Social Comparison Processes. Human Relations, 7(2), 117-140;

[8] Golnar-Nik, P., Farashi, S. \& Safari, M. S. (2019), The Application of EEG Power for the Prediction and Interpretation of Consumer Decision-making: $A$ Neuromarketing Study. Physiology \& Behavior, 207, 90-98;

[9] Haeckel, S. H., Carbone, L. P. \& Berry, L. L. (2003), How to Lead the Customer Experience. Marketing Management, 12(1), 18-18;

[10] Kohut, S. A. \& Riddell, R. P. (2009), Does the Neonatal Facial Coding System Differentiate between Infants Experiencing Pain-Related and Non-Pain-Related Distress?. The Journal of Pain, 10(2), 214-220;

[11] Kotler, P., Kartajaya, H., Setiawan, I. (2016), Marketing 4.0 - Moving from

Traditional to Digital, John Wiley and Sons, Hoboken, New Jersey; 
Adrian Micu, Alexandru Capatina, Angela-Eliza Micu, Marius Geru, Kamer Ainur Aivaz, Mihaela-Carmen Muntean

[12] Kraus, S., Ribeiro-Soriano, D. \& Schüssler, M. (2018), Fuzzy-set Qualitative Comparative Analysis (Fsqca) in Entrepreneurship and Innovation Research-The Rise of a Method. International Entrepreneurship and Management Journal, 14(1), 15-33;

[13] Levallois, C., Smidts, A. \& Wouters, P. (2019), The Emergence of Neuromarketing Investigated through Online Public Communications (2002-2008). Business History, 1-40;

[14] Mañas-Viniegra, L., Núñez-Gómez, P. \& Tur-Viñes, V. (2020), Neuromarketing as a Strategic Tool for Predicting How Instagramers Have an Influence on the Personal Identity of Adolescents and Young People in Spain. Heliyon, 6(3), e03578;

[15] Mič́́k, M. \& Kunešová, H. (2020), Using an Eye Tracker to Optimise Career Websites as a Communication Channel with Generation Y. Economic ResearchEkonomska Istraživanja, 1-24;

[16] Moreno, M., D'Angelo, J. \& Whitehill, J. M. (2016), Social Media and Alcohol: Summary of Research, Intervention Ideas and Future Study Directions. Media and Communication, 4(3), 50-59;

[17] Morin, C. (2011), Neuromarketing: The New Science of Consumer Behavior. Society, 48(2), 131-135;

[18] Muncy, J. A. (1996), Measuring Perceived Brand Parity. ACR North American Advances, 23(1);

[19] Ohme, R., Matukin, M. \& Pacula-Lesniak, B. (2011), Biometric Measures for Interactive Advertising Research. Journal of Interactive Advertising, 11(2), 60-72; [20] Ruanguttamanun, C. (2014), Neuromarketing: I Put Myself into a fMRI Scanner and Realized that I Love Louis Vuitton Ads. Procedia - Social and Behavioral Sciences, 148, 211-218;

[21] Schmitt, B. (1999), Experiential Marketing: A New Framework for Design and Communications. Design Management Journal, 10(2), 10-16;

[22] Schouten, A. P., Janssen, L. \& Verspaget, M. (2020), Celebrity vs. Influencer Endorsements in Advertising: The Role of Identification, Credibility, and ProductEndorser Fit. International Journal of Advertising, 39(2), 258-281;

[23] Sheldon, P. \& Bryant, K. (2016), Instagram: Motives for its Use and Relationship to Narcissism and Contextual Age. Computers in Human Behavior, 58, 89-97;

[24] Sheth, J. \& Sisodia, R. (2012), The 4 A's of Marketing: Creating Value for Customer, Company and Society. Routledge;

[25] Tranfield, D., Denyer, D. \& Smart, P. (2003), Towards a Methodology for Developing Evidence-informed Management Knowledge by Means of Systematic Review. British journal of management, 14(3), 207-222;

[26] Voorveld, H. A. (2019), Brand Communication in Social Media: A Research Agenda. Journal of Advertising, 48(1), 14-26;

[27] Wang, W., Liang, Q., Mahto, R. V., Deng, W. \& Zhang, S. X. (2020), Entrepreneurial Entry: The Role of Social Media. Technological Forecasting and Social Change, 161, 120337. 